\title{
Optimizing sports performance through relaxation and visualization techniques. Adaptation and limitation in online practice
}

\section{Optimizarea performanțelor sportive prin tehnici de relaxare și vizualizare. Adaptare și limitare în practica online}

\author{
NICOLESCU Alexandra-Cristina, Doctorandă \\ Universitatea Pedagogică de Stat „Ion Creangă ” din Chișinău \\ NICOLESCU Alexandra-Cristina, $P h D$ Student \\ Ion Creangă State Pedagogical University of Chișinău \\ E-mail: drd.alexandranicolescu@gmail.com \\ ORCID iD: 0000-0003-2821-6607 \\ DOI: $10.46728 /$ c.18-06-2021.p151-156 \\ CZU: 796.015:159.9
}

Rezumat: Atingerea și menținerea unui nivel înalt de performanță reprezintă un obiectiv dorit de către sportivi și întreaga echipă de pregătire, indiferent de ramura de sport practicată. Performanța sportivă implică un antrenament zilnic atât din punct de vedere fizic, cât și psihologic. Scăderea performanței la sportivi se poate manifesta prin: lipsa concentrării, tulburări de alimentație și somn, stare de oboseală accentuată, anxietate, tensiune musculară etc. [7, p. 247]. Tehnicile de relaxare au fost utilizate în domeniul sportiv cu precădere în vederea îmbunătățirii performanței, a gestionării anxietății și pentru stimularea procesului de recuperare după antrenamente și concursuri [23, p. 406]. Printre factorii psihologici importanți pentru atingerea performanței, putem enumera: motivația (internă şi externă), interesul, controlul emoțional, încrederea în sine, capacitatea de concentrare, etc.

Cuvinte-cheie: sport, performanță, tehnici de relaxare.

Abstract: Achieving and maintaining a high level of performance is a goal desired by athletes and their entire training team, regardless of the chosen sport branch. Sports performance involves daily training both physically and psychologically. Decreased performance in athletes can be manifested by: lack of concentration, eating and sleep disorders, increased fatigue, anxiety, muscle tension, etc. [7, p. 247]. Relaxation techniques have been used in the sports field mainly to improve performance, manage anxiety and enhance the recovery process after training and competitions [23, p. 406]. Among the psychological factors important for achieving performance, we can find: motivation (internal and external), interest, emotional control, selfconfidence, concentration, etc.

Keywords: sport, performance, relaxation techniques.

\section{Introducere}

Conform M. Epuran, I. Holdevici \& F. Tonița (2001) „,performanța sportivă reprezintă rezultatul obținut într-o activitate specifică, de regulă într-un concurs, desemnată printr-o cifră sau un calificativ pe scara valorilor" [3, p. 37]. Inafară de sportiv, care este principalul element constitutiv al echipei și „principalul subiect generator al performanței” [3, p. 41], performanța este urmărită și trăită atât de către către antrenor, cât și de către întreaga echipă de pregătire (psiholog, medic, manager etc.). Nevoia de performanță se manifestă astfel, printr-un efort comun către obținerea unui rezultat remarcabil.

Printre trăsăturile sau factorii principali asociați cu performanța sportivă se numără:

- ereditatea, aptitudinea, antrenamentul tehnic și tactic [15]; 
- factorii de personalitate (introversie-extraversie, nevrotism și stabilitate emoțională) [1, 22];

- $\quad$ experințele anterioare, starea de antrenament, interesul și motivația [3, p. 45];

Astfel, pentru obținerea performanței sportive, pe lângă dezvoltarea și valorificarea maximă a aptitudinilor motrice precum: viteza, rezistența, forța, mobilitatea, este necesar să fie luaţi în considerare și factorii psihologici, care sunt de cele mai multe ori esenţiali [13], dar și pregătirea tehnico-tactică, capacitatea de recuperare și odihnă, hidratarea și nutriția, vârsta, factorii de mediu. Printre factorii psihologici importanți pentru atingerea performanței, putem enumera: motivația (internă și externă), interesul, controlul emoțional, capacitatea de concentrare, încrederea în sine etc.

Drumul către atingerea performanței implică un nivel ridicat de stres și anxietate în situații precum: înțelegerea și depășirea eșecurilor, acceptarea greșelilor, controlul greutăţii corporale, oboseala accentuată, managementul durerii și toate probleme care pot apărea pe parcursul vieții de sportiv. T. Vasile (2016) subliniază faptul că în situații de stres, impactul negativ asupra planului mental și cel emoțional poate fi imens, iar găsirea mecanismelor adecvate de adaptare la astfel de situații necesită timp, răbdare, înţelegere și descoperirea resurselor interioare menite să restabilească echilibrul [19, p. 26].

\section{Tehnici de relaxare și imagerie utilizate în pregătirea sportivilor}

Semnificația termenului de relaxare, în sens larg, poate fi explicat prin „,deconectare generală a individului de activitatea sa cotidiană" [21, p. 115], iar dacă facem referire strictă la sensul restrâns al termenului „,relaxarea este o tehnică psihoterapeutică și autoformativă [...] care urmărește realizarea unei decontrații musculare și nervoase [...] cu scopul economisirii energiei fizice și psihice, a creșterii rezistenței la stres a organismului și diminuării efectelor negative ale stresului deja instalat" [21, p. 115].

Practica relaxării presupune: un ambient sigur și liniștit, o postură adecvată, eliberarea de gândurile și tensiunea de peste zi, practica respirației, fixarea și cultivarea atenției, etc. [20, p.3031].

Printre cele mai utilizate tehnici de relaxare și/sau imagerie în pregătirea sportivilor putem enumera: antrenamentul autogen, relaxarea musculară progresivă, antrenamentul psihoton, biofeedback-ul.

\section{a. Antrenamentul autogen}

Antrenamentul autogen (training-ul autogen) este o tehnică de relaxare introdusă de către medicul psihiatru Johannes Heinrich Schultz în anul 1932 [14]. În practica antrenamentului autogen, subiecților li se transmit sugestii repetate de greutate și mai apoi de căldură în tot corpul. Aceste sugestii au rolul de a stimula relaxarea musculară și ulterior, prin senzația de căldură este înlesnită vasodilatația. La final, exercițiul se încheie cu anularea stării autogene. Această tehnică de relaxare este indicată pentru atât în vederea obținerii stării de relaxare fizice, cât și mentale.

\section{b. Relaxarea musculară progresivă}

Edmund Jacobson (1938) a elaborat Tehnica de Relaxare Musculară Progresivă pornind de la studiul asupra sistemului muscular, mai precis a fibrei musculare, care aflată în relaxare, în absența totală a încordării, era văzută de autor ca o manifestare opusă stării de tensiune musculară [5, p. 522]. În practica acestei tehnici de relaxare atenția se centrează la început asupra procesului respirator, ulterior urmărinu-se progresiv starea de încordare-relaxare a anumitor grupe musculare și senzațiile pe care subiectul le resimte pe parcursul exersării.

\section{c. Antrenamentul psihoton}

Antrenamentul psihoton este utilizat pentru creșterea performanței sportive prin intermediul unor stimuli psihologici și pentru echilibrarea și calmarea sportivului înainte de o competiţie. Antrenamentul psihoton are drept scop „optimizarea mecanismelor de adaptare la situațiile de antrenament și, mai ales de concurs" [3, p. 355]. Epuran et al. (2011) specifică faptul 
că se face o delimitare între antrenamentul autogen și cel psihoton, la cel din urmă utilizându-se în plus o etapă de mobilizare și activare a sportivului prin exerciții de vizualizare și imagerie care sunt caracteristice sportului practicat de acesta și care îl vor ajuta în acest fel să facă față provocărilor competiţionale [3, p. 355].

\section{d. Biofeedback}

În biofeedback sunt utilizate imagini și sunete cu scopul de a obține o stare de relaxare și de bine la nivel fizic și psihic. Prin tehnica biofeedback sportivii pot învăța să-și controleze anumiți paramentrii și funcții prin intermediul sistemului nervos. Astfel, se poate urmări relaxarea mușchilor, controlul ritmului cardiac și al respirației, atenuarea durerilor, reglarea tensiunii arteriale, pentru a obține o stare e bine și pentru a crește performanțele în activitate. Subiecților li se aplică senzori electrici pe diferite zone ale corpului și sunt conectați la un aparat care înregistrează starea fiziologică a organismului. E. Peper \& F. Shaffer (2010) indică faptul că bazele primei Societăți de Biofeedback au fost puse în Statele Unite ale Americii (California), la iniţiativa cercetătoarei Barbara Brown [11, p. 142].

\section{Studii cu privire la tehnicile de relaxare și performanța sportivă}

Scăderea performanței la sportivi se poate manifesta prin: lipsa concentrării, tulburări de alimentație și somn, stare de oboseală accentuată, anxietate, tensiune musculară etc. [7, p. 247]. În ceea ce privește utilizarea tehnicilor de relaxare în domeniul sportiv, intervețiile specifice au avut ca scop principal îmbunătăţirea performanței, gestionarea anxietății și stimularea procesului de recuperare după antrenamente și concursuri [23, p. 406].

Conform studiului realizat de către S.D. Maniar și colaboratorii (2001), atunci când sportivii se confruntă cu probleme precum scăderea performanței, aceștia solicită ajutorul antrenorului și al personalului specializat, având încredere în tehnicile de imagerie și stabilire a obiectivelor [8, p. 205].

Analizând relația dintre tehnicile de relaxare și performanța sportivă, V.A. Parnabas et al. (2014) sunt de părere că tehnicile de relaxare se dovedesc a fi utile nu numai în vederea scăderii nivelului de anxietate percepută foarte des de către sportivi, mai ales în cadrul competiţiilor, dar și pentru creșterea performanței. [9, p. 108].

M. Kellmann și colaboratorii (2018) sunt de părere că tehnicile de relaxare pot fi utilizate în direcții precum autoreglarea, în procesul de recuperare și pentru optimizarea aptitudinilor sportive. Autorii subliniază faptul că integrarea în programul de antrenament a practicii tehnicilor de relaxare împreună cu cele de respirație poate îmbunătății starea de bine a sportivului prin conștientizarea și păstrarea stării de echilibru interior [7, p. 247].

Studiind relația dintre performanță și tehnicile de relaxare M. Pelka et al. (2016) au realizat un studiu la care au participat un număr de 27 de studenți sportivi și în cadrul căruia au fost utilizate tehnici precum: relaxarea musculară progresivă, respirația sistematică, yoga. Intervenția s-a desfășurat pe o perioadă de cinci săptămâni, ședințele desfãșurându-se o dată pe săptămână. Rezultatele studiului au indicat faptul că performanțele subiecților au fost îmbunătățite în urma programului de intervenție propus, de asemenea autorii indicând utilizarea preponderent a tehnicilor de respirație sistematică [10, p. 216].

Solberg și colaboratorii (2000) au realizat un studiu la care au participat un număr de 31 de alergători din Oslo care au fost împărțiţi în trei grupuri, astfel: primul grup, în are a fost utilizată meditaţia $(n=11)$, al doilea grup, în care a fost utilizat antrenamentul autogen $(n=10)$ și grupul de control $(n=10)$ [16, p. 269]. Rezultatele studiului au indicat faptul că practica meditației poate scădea concentrația nivelului de lactat din sânge, autorii observând și un nivel bun de complianță al subiecților în relație cu tehnicile utilizate, însă aceștia sunt de părere că este necesar un studiu ulterior pe un număr mai mare de subiecți și având ca scop managementul stresului [16, p. 272].

Intervenţiile de tip mindfulness se dovedesc a fi utile în cazul sportivilor ce practică golful, tirul cu arcul și pentru alergători [17], Thompson et al. (2011) realizând un studiu privind 
efectele pe termen lung ale intervențiilor de tip mindfulness în ceea ce privește creșterea performanței la sportivi. La studiul iniţial publicat în anul 2009 [2] au participat un număr de 21 de practicanți de golf, 11 practicanți ai tirului cu arcul și 25 de alergători pe distanțe lungi. Din totalul de 52 de subiecți inițiali, la un interval de un an de zile a fost realizat un follow-up la care au participat un număr de 25 de subiecți, astfel: 8 practicanți de golf, 4 practicanți de tir cu arcul şi 13 alergători [17, p. 102]. Rezultatele studiului indică o îmbunătățire semnificativă a performanței observată la alergătorii pe distanțe lungi, autorii concluzionând faptul că acesta este primul studiu de tip follow-up care analizează rolul intervențiilor de tip mindfulness pentru creșterea performanțelor sportive [17, p. 110].

N. Pusenjak și colaboratorii (2015) au analizat efectele terapiei de tip biofeedback asupra performanțelor sportive. La studiu au participat un număr total de 39 de subiecți cu vârsta cuprinsă între 16 și 34 de ani, 18 sportivi de performanță au făcut parte din grupul experimental (4 femei și 14 bărbați) și s-a desfășurat pe o perioadă de 8 săptămâni. Rezultatele obținute au indicat faptul că intervențiile prin biofeedback pot îmbunătătii performanța sportivilor și pot contribui la un optimizarea controlului psiho-fiziologic [12, p. 11].

\section{Comunicarea online. Adaptare și limitare în perioada pandemiei}

Deși traversăm cu toții o perioadă extrem de dificilă, este indicat să observăm faptul că adaptarea la folosirea preponderent a mijloacelor de comunicare online se poate să aibă anumite avantaje, precum:

- câștigul în ceea ce privește factorul timp - programul unui sportiv este deosebit de încărcat, astfel, prin adaptarea ședințelor de psihoterapie în mediul onine se va elimina pierderea de timp;

- eliminarea barierelor geografice - dacă sportivul participă la o competiție ce se desfășoară înafara granițelor țării de origine va fi mult mai ușor de păstrat legătura cu acesta;

- asigurarea unei stări de confort -prin utlizarea calculatorului din propria casă sau un spațiu pe care îl alege sportivul și care îi dă o stare de liniște și siguranță;

- utilizarea platformelor online care integrează activitatea unitară a mai multor specialități precum: medicină sportivă, psihologie sportivă, recuperare medicală etc.

Odată cu utilizarea mediului online apar și anumite dificultăți sau neajunsuri de care suntem nevoiți să ținem cont:

- conexiunea slabă sau inexistentă de internet face imposibilă comunicarea online.

- imposibilitatea de a observa limbajul non-verbal;

- lipsa conexiunii umane;

- oboseală accentuată;

În cazul sportivilor, perioada de pandemie a fost una restrictivă, marea majoritate a concursurilor au fost amânate, o parte din timp sălile de sport au fost închise, ceea ce a însemnat o perioadă de involuție în ceea ce privește performanța sportivilor. În perioada post-pandemie recuperarea la forma fizică iniţială se poate dovedi extrem de dificilă și poate depinde și de perioada de timp cât sportivul a stat departe de sala de antrenamente.

\section{Concluzii}

În practica zilnică sportivii se pot confrunta cu un nivel ridicat de anxietate și stres, cu perioade în care stima de sine este scăzută, iar gândurile negative sunt predominate, mai ales atunci când se află înaintea unei competiţii importante. T. Vasile (2018) este de părere că atunci când ne confruntăm cu situații anxiogene, un mod de gândire pozitiv, orientat către aspectele frumoase ale vieții, precum și construirea unei imagini de sine pozitive, pot să facă diferența între un eșec și o mare realizare [18, p. 27].

Tehnicile de respirație pot fi integrate cu succes alături de tehnicile de relaxare în programul de pregărire a sportivilor $[7,10]$. Tehnici precum: antrenamentul autogen, relaxarea 
musculară progresivă, antrenamentul psihoton sau biofeedback-ul pot fi utilizate în programul de pregătire fizică și psihologică a sportivilor, însă unele pot fi adaptate la comunicarea online, în timp ce altele fac necesară prezența fizică a subiecților.

Putem observa faptul că există atât avantaje, cât și dezavantaje în utilizarea mediului online, însă suntem de părere că, deși activitatea unui psiholog poate fi adaptată la cerințele și necesitățile sportivilor, activitatea acestora din urmă nu se poate desfășura cu succes decât în sala de antrenament și în spațiul de concurs, față în față cu antrenorul, aproape de publicul spectator, ceea ce ne face să ne gândim la faptul că sunt anumite profesii care întâmpină dificultăți mai mari la adaptarea la mediul online și probabil că va apărea necesitatea găsirii de soluții pentru rezolvarea acestora.

\section{BIBLIOGRAFIE}

1. COOPER, L. Athletics, activity and personality: a review of the literature. Research Quarterly, 1969, 40(1), pp. 17-22. DOI: 10/1080/10671188.1969.10616637.

2. DE PETRILlO, L. A., KAUFMAN, K., GLASS, C. R., \& ARNKOFF, D. B. Mindfulness for long-distance runners: An open trial using Mindful Sport Performance Enhancement (MSPE). Journal of Clinical Sport Psychology, 2009, 3(4), pp. 357-376. DOI: $10.1123 /$ jcsp.3.4.357.

3. EPURAN, M., HOLDEVICI, I., TONIȚA, F.. Psihologia sportului de performanță: teorie și practică. București: Editura Fest, 2001. 467 p. ISBN 973-85143-0-4.

4. JACOBSON, E. Progressive relaxation. Chicago: University of Chicago Press, 1938. 493 p. ISBN 978-0226390581.

5. JACOBSON, E. Progressive Relaxation. The American Journal of Psychology. 100(3/4) Special Centennial Issue, 1987, pp. 522-537. DOI: 10.2307/1422693.

6. KAUFMAN, K., GLASS, C. R., \& ARNKOFF, D. B. An evaluation of Mindful Sport Per-formance Enhancement (MSPE): A new mental training approach to promote flow in athletes. Journal of Clinical Sport Psychology, 2009, 4(4), pp. 334-356. DOI: 10.1123/jcsp.3.4.334.

7. KELLMANN, M., PELKA, M., BECKMAN, J.. Psychological relaxation techniques to enhance recovery in sports. In M. Kellmann \& J. Beckmann (Eds.), Sport, recovery, and performance: Interdisciplinary insights, pp.247-259, United Kingdom: Routledge/Taylor \& Francis Group, 2018. 270 p. ISBN 978-1315-2681-49.

8. MANIAR, S. D., CURRY, L. A., SOMMERS-FLANAGAN, J., WALSH, J. A. StudentAthlete Preferences in Seeking Help When Confronted with Sport Performance Problems. The Sport Psychologist, 2001, 15(2), pp. 205-223. DOI: 10.1123/tsp.15.2.205.

9. PARnABAS, V. A., MAHAMOOD, Y., PARnABAS, J., ABDUllah, N. M. The Relationship between Relaxation Techniques and Sport Performance. Universal Journal of Psychology, 2014, 2(3), pp. 108-112. DOI: 10.13189/ujp.2014.020302.

10. PELKA, M., KOLling, S., FERRAUTI, A., MEYER, T., PFEIFFER, M., KELLMANN, M.. Acute effects of psychological relaxation techniques between two physical tasks. Journal of Sports Sciences, 2017, 35(3), pp. 216-223. DOI: 10.1080/02640414.2016.1161208.

11. PEPER, E., SHAFFER, F.. Biofeedback History: An Alternative View. Biofeedback, 2010, 38(4), pp. 142-147. DOI: 10.5298/1081-5937-38.4.03.

12. PUSENJAK, N., GRAD, A., TUSAK, M., LESKOVSEK, M., SCHWARZLIN, R. Can biofeedback training of psychophysiological responses enhanceathletes'sport performance? A practitioner's perspective. The Physician and Sports Medicine, Early Online, 2015, pp. 1-13. DOI: 10.1080/00913847.2015.1069169. 
13. RAGLIN, J. S. Psychological factors in sport performance. Sports Medicine, 2001, 31(12), pp. 875-890. DOI: 10.2165/00007256-200131120-00004.

14. SCHULTZ, J. H. Das Autogene Training. Konzentrative Selbstentspannung. Leipzig: Thieme. 1932. $305 \mathrm{p}$.

15. SINGER, R. N. The Training of Highly Skilled Athletes: Psychological Consideration, In: Collection of papers, IV-th ISSF Congress, Praha, 1977.

16. SOLBERG, E. E., INGJER, F., HOLEN, A., SUNDGOT-BORGEN J., NILSSON, S. Stress reactivity to and recovery from astandardised exercise bout: a study of 31 runnerspractising relaxation techniques. British Journal of Sports Medicine, 2000, 34(4), pp. 268-272. DOI: 10.1136/bjsm.34.4.268.

17. THOMPSON, R. W., KAUFMNAN, K. A., DE PETRILlO, L. A., GLASS, C. S., ARNKOFF, D. B. One Year Follow-Up of Mindful Sport Performance Enhancement (MSPE) With Archers, Golfers, and Runners. Journal of Clinical Sport Psychology, 2011, 5(2), pp. 99-116. DOI: 10.1123/jcsp.5.2.99.

18. VASILE, T. The relation between Anxiety, Automatic Thoughts Adjustment and Emotional Control. Journal of Experiential Psychotherapy, 2018, 21(4((84)), pp. 23-28.

19. VASILE, T. The impact of the personal development training on reducing the perceived level of negative emotions and the perceived level of depression and improving the perceived level of the positive emotions. Romanian Journal of Experimental Applied Psychology, 2016, 7(4), pp. 23-35.

20. VASILE, T. Flacăra Violetă - o terapie complementară holistic-integrativă, București: Editura Pro Editură și Tipografie. 2007, 248 p. ISBN 978-973-145-090-2.

21. VASILESCU, I. P., HOLDEVICI, I. Activitatea sportivă. Decizie, autoreglare, performanță. Editura Sport-Tursm, 1988. 176 p.

22. WARBURTON, F. W., KANE, J. E. Personality related to sport and physical activity. In: KANE, John Edward (ed.), Readings in physical education. London: P.E. Association, 1966, pp. 61-89. 237 p. ISBN 07100720749780710072078.

23. WEINBERG, R., COMAR, W. The effectiveness of psychological interventions in competitive sport. Sports Medicine, 1994, 18(6), pp. 406-418. DOI: 10.2165/00007256199418060-00005. 